\title{
Drug survival and causes of discontinuation of anti-TNF in ankylosing spondylitis: the Tunisian experience
}

\author{
Essafi F, Saidane O, Mahmoud I, Ben Tekaya A, Tekaya R, Abdelmoula L \\ Department of Rheumatology, Charles Nicolle hospital
}

Background: Ankylosing spondylitis (AS) is a chronic inflammatory disease predominantly affecting the sacroiliac joints and spine. Very limited observational data regarding the long-term survival on treatment are available.

The focuses of this work were to study and to compare drug retention between the 3 anti-TNF marketed in Tunisia.

Methods: We achieved a retrospective descriptive and comparative monocentric study, on 23 patients, with AS (according to Amor criteria and ASAS 2009), during 12 years (2004-2015). The patients were treated with at least one antiTNF, during at least 6 months. Drug survival was analysed by means of Kaplan-Meier curves.

\section{Results:}

\begin{tabular}{|l|l|}
\hline Patients & 23 \\
\hline Sexe-ratio & 4,75 \\
\hline Age (years) & $40,7 \pm 9,6$ \\
\hline Age at disease onset (years) & $28,52 \pm 11,36$ \\
\hline mean disease duration (years) & $9,6 \pm 7,17$ \\
\hline $\begin{array}{l}\text { median duration of prescription of anti-TNF } \\
\text { therapy (years) }\end{array}$ & 4,25 \\
\hline
\end{tabular}

\begin{tabular}{|ll|}
\hline Reasons of discontinuing & cases \\
\hline lack of efficacy & 3 \\
\hline adverse event & 3 \\
\hline lost from follow up & 1 \\
\hline
\end{tabular}

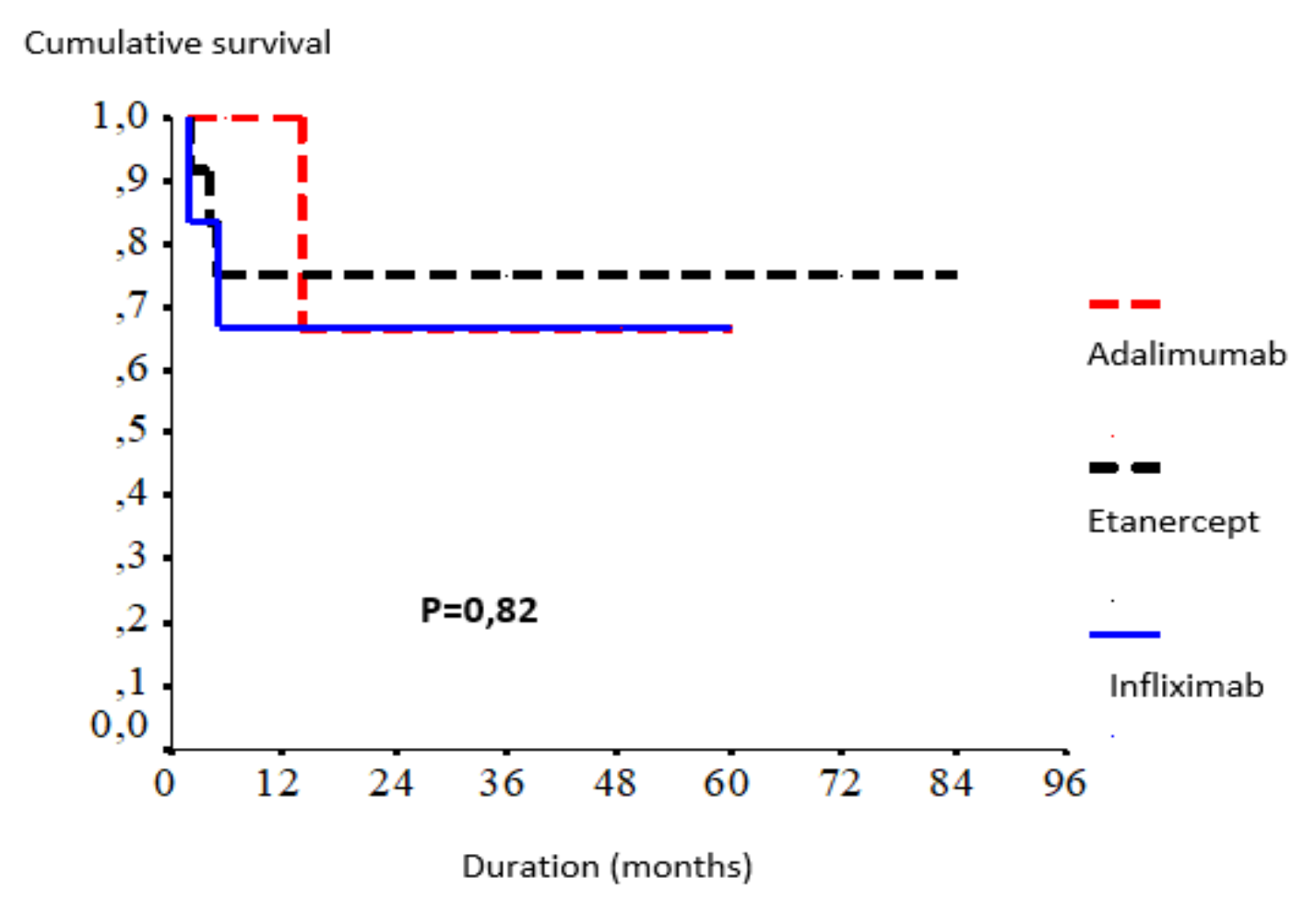

Figure 2: Eight-year drug survival rates by TNF inhibitor in ankylosing spondylitis .

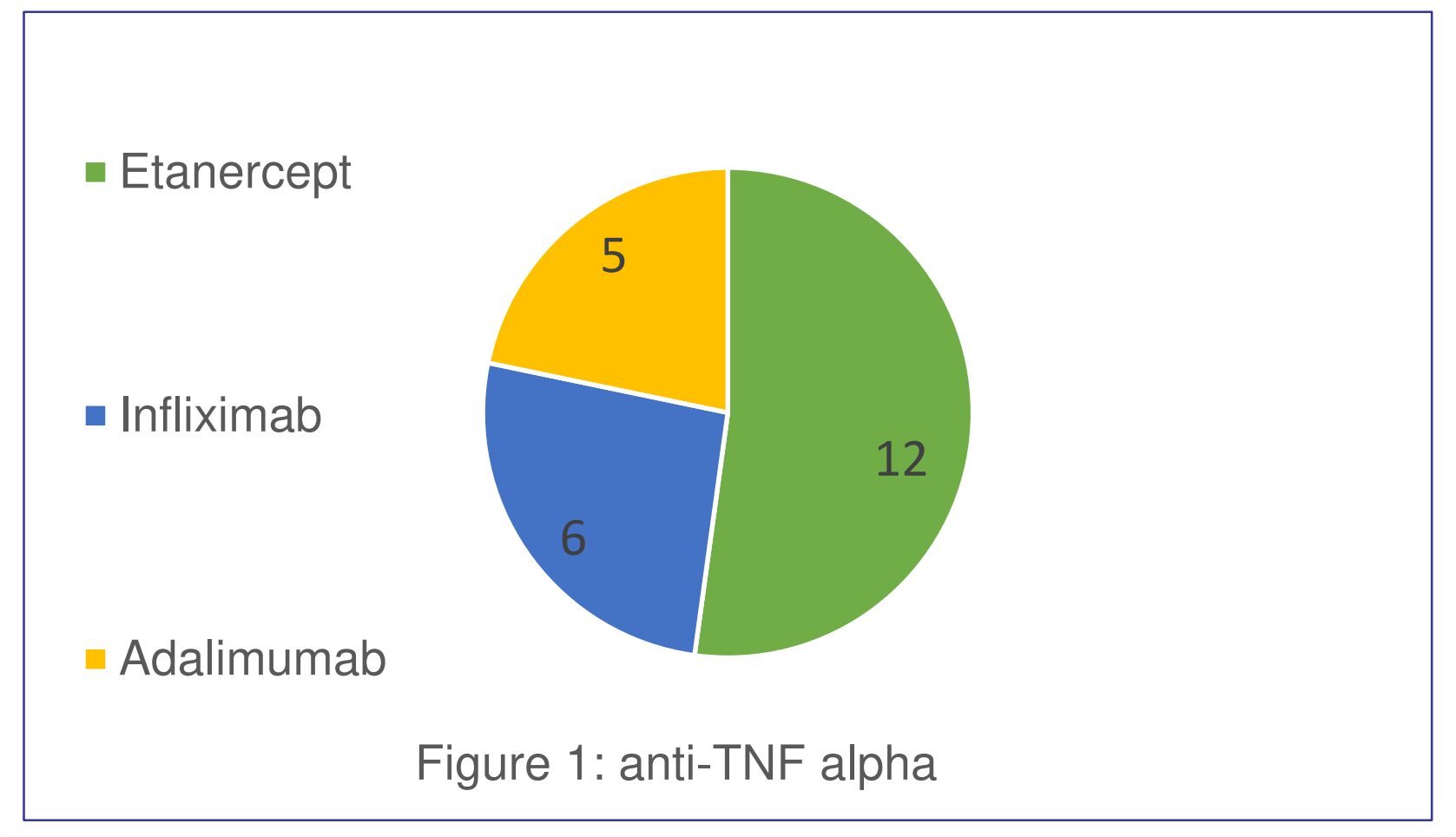

Two patients on ETN discontinued the biological drug because of paradoxical effects, and one patient on IFX discontinued the drug for urogenital tuberculosis.

Discussion: Carmona and Gómez-Reino [1] found a 1-year TNF alpha inhibitor survival rate of $88 \%$ among 657 Spanish patients with AS, whereas a Norwegian study [2] among 249 patients with AS reported a survival rate of $77,5 \%$. According to the DANBIO registry [3], one- and 2year survival rates were $74 \%$ and $63 \%$, respectively. The crude retention rates were similar among patients receiving IFX, ADA and ETN $(p=0.2)$.

Conclusion: This study demonstrated that anti-TNF showed a comparable drug retention in AS treatment. To avoid secondary effects leading to treatment discontinuation, we recommend a close monitoring,

1-Carmona L, Gómez-Reino JJ. Survival of TNF antagonists in spondylarthritis is better than in rheumatoid arthritis. Data from the Spanish registry BIOBADASER. Arthritis Res Ther 2006;8:R72

2- Heiberg MS, Koldingsnes W, Mikkelsen K, et al. The comparative one-year performance of anti-tumor necrosis factor alpha drugs in patients with rheumatoid arthritis, psoriatic arthritis, and ankylosing spondylitis: results from a longitudinal, observational, multicenter study. Arthritis Rheum 2008;59:234-40.

3-Glintborg B, Ostergaard M, Krogh NS, Dreyer L, Kristensen HL, Hetland ML. Predictors of treatment response and drug continuation in 842 patients with ankylosing spondylitis treated with anti-tumour necrosis factor: results from 8 years' surveillance in the Danish nationwide DANBIO registry. Ann Rheum Dis. 2010;69(11):2002-8 